DOI 10.37882/2223-2982.2020.06.32

\title{
ВЗАИМОСВЯЗЬ ОБРАЗОВАТЕЛЬНОЙ И СОцИОКУЛЬТУРНОЙ ИНКЛЮЗИИ
}

\section{CONNECTION BETWEEN SOCIO-CULTURAL AND EDUCATIONAL INCLUSION \\ M. Suchkov}

Summary: The author studies the connection between educational and socio-cultural inclusion. The author reveals the philosophical and theoretical aspects of inclusive education. The definition of the concepts «inclusive education», "social inclusion», «cultural inclusion», «sociocultural inclusion» are given. The author investigates common ground between educational and socio-cultural inclusion at three levels: global, local and personal. The author describes the «area of socio-cultural inclusion» which appears at the level of educational organization, intrapersonal and interpersonal levels.

Keywords: inclusive education, children with disabilities, socio-cultural inclusion, the area of socio-cultural inclusion.

\author{
Сучков Максим Александрович \\ К.э.н., дочент, Кыргызский филиал ФГБОУ ВО “Казанский \\ национальный исследовательский технологический \\ университет", г. Кант, Кыргызская Республика \\ maksim-suchkov@inbox.ru
}

Аннотация: В статье автором раскрыта взаимосвязь между образовательной и социокультурной инклюзией. Автор раскрывает философские и теоретические аспекты инклюзивного образования. Дано определение понятиям «инклюзивное образование», «социальная инклюзия», «культурная инклюзия», «социокультурная инклюзия». Автор рассматривает точки соприкосновения между инклюзивным образованием и социокультурной инклюзией на трех уровнях: глобальном, локальном и личностном. Автор описывает «область социокультурного включения», возникающую на уровне образовательной организации, на внутриличностном и межличностном уровнях.

Ключевые слова: инклюзивное образование, дети с ограниченными возможностями здоровья (ОВЗ), социокультурная инклюзия, область социокультурного включения.

\section{Введение}

онятие «инклюзия» (inclusion - включение) является достаточно многогранным и в современной науке рассматривается с социальной, культурной, образовательной, лингвистической и других позиций. Говоря с философской точки зрения, инклюзия представляет собой определенный способ мышления и действия, благодаря которому человек чувствует себя принятым, ценным для общества и в определенной безопасности. Через признание, участие и поддержку развивается инклюзивное общество - общество равных прав и возможностей.

Наиболее значимым условием создания инклюзивного общества является развитие инклюзивного образования. Через развитие инклюзивного образования меняются отношения между людьми, осуществляется внутриличностное развитие, претерпевает изменения культура образовательной организации. Человек активно включается в социальную жизнь, обогащается его культурное мировоззрение, а главное, он становится значимой частью этого общества. Следовательно, развитие инклюзивного образования тесно связано с социокультурной инклюзией. Проведя исследования и изучив отечественный и зарубежный опыт, мы определили точки соприкосновения «образовательной» и «социокультурной» инклюзии, выявили их тесную взаимосвязь.

\section{ИнкАюзивное образование: философско-теоретические аспекты}

Если мы обратимся к определению понятия «инклюзивное образование» такими международными организациями, как ЮНЕСКО, ЮНИСЕФ, ООН, то заметим одну общую тенденцию. Инклюзия в документах данных организаций представляет собой обеспечение равных образовательных прав для всех лиц с различными образовательными потребностями. С. Стабс рассматривает «инклюзивное образование» как процесс, направленный на создание образовательной системы, отвечающей нуждам «всех людей», и признавая при этом, что до сих пор многие остаются «исключенными» из такой системы [1]. Д.3. Ахметова [2], Е.Н. Пургина [3], Н.М. Назарова [4] раскрывают философские и культурологические аспекты инклюзивного образования. Так, ключевым принципом инклюзивного образования, является то, что каждый человек, независимо от способностей и достижений, имеет право на образование и поддержание приемлемого уровня знаний, самовыражение и личный прогресс, общение, дружбу и поддержку [2].

П. Пандит [5], рассматривая особенности инклюзивного образования, отмечает, что инклюзия начинается с признания права детей и их семей на доступ к высококачественному образованию. Инклюзивная практика призвана выявлять и устранять барьеры на пути полного принятия, участия и обучения всех детей. Она также 
направлена на изменение политики государства, организации, школы.

Раскрывая основные принципы педагогики инклюзивного образования, Л. Флориан и Дж.Спрэт, отмечают следующее:

1. Различия между детьми должны учитываться как существенный аспект человеческого развития при организации обучения.

2. Важна вера учителей в то, что они достаточно квалифицированы / способны обучать всех детей.

3. Важен непрерывный рост и поиск новых творческих способов работы с разными детьми.

Опираясь на данные принципы, авторы разработали три курса в профессиональной подготовке педагогов:

1. «Понимание основ обучения в инклюзивном класce».

2. «Понимание социальной справедливости».

3. «Становление активным специалистом» [6].

Обращаясь к философским основам инклюзивного образования, важно отметить то, какую большую роль сыграли исследования Л.С. Выготского [7]. Его идеи несут огромную актуальность в настоящее время. Основываясь на них, мы делаем вывод о том, что социокультурная среда является важнейшим фактором в становлении личности ребенка. Важен процесс взаимодействия биологических, социальных и педагогических факторов при построении образовательной системы, учитывающей потребности и возможности всех детей. Отсюда следует вывод, что социальная и образовательная инклюзия неразрывно связаны между собой.

\section{Сочиокультурная инклюзия}

Социальная инклюзия - процесс расширения возможностей для социального участия, повышения уровня жизни общества. В контексте социальной инклюзии укрепляются социальные связи, усиливаются сплоченность, интеграция и солидарность. Также социальная инклюзия открывает доступ людей к участию во всех сферах социальной жизни: посещение образовательных и культурных учреждений, возможности трудоустройства, получение социальной помощи от государства, участие в различных мероприятиях школы, вуза, города, страны. Самым главным принципом социальной инклюзии является то, что люди разделяют общие ценности.

М. Робо (Университет г. Тирана, Албания) выделяет следующие приоритеты и ценности, лежащие в основе социальной инклюзии:

1. Каждый из нас готов к «включению в общество». Люди не обязаны соответствовать ряду критериев для того, чтобы быть допущенными в социум.

2. Все люди нуждаются в поддержке (некоторым нужна более сильная поддержка, чем другим).

3. Каждый человек имеет право на обучение (все способны обучаться).

4. Каждый человек может внести свой вклад в развитие общества (нам необходимо признавать, поощрять и ценить вклад каждого человека, включая наш собственный).

5. Каждый человек, несмотря на свои возможности и способности, имеет право на общение.

6. Вместе мы сильнее. Мы не мечтаем о том мире, где все похожи друг на друга. Разнообразие - это наше главное достоинство [8].

Социальная инклюзия связана и с культурной инклюзией. По определению ЮНЕСКО культурная инклюзия направлена на обеспечение участия в культурной жизни общества, доступа к культуре, предоставление прав на выражение через культуру [9].

Таким образом, социокультурная инклюзия понимается как многомерный процесс, направленный на создание условий для полного и активного участия каждого члена общества в главных аспектах жизни (социальной, экономической, культурной). Ступени данного процесса являются взаимосвязанными. Учащиеся приобретают знания, навыки, необходимые ресурсы в образовательной системе. Далее происходит процесс их социальной интеграции в другие сферы жизни. При этом ряд таких факторов, как состояние здоровья, этническая и религиозная принадлежность, языковая картина мира, могут способствовать или препятствовать социальной интеграции. Важно понять причины социальной исключенности, обеспечить равные права и возможности уже на уровне «образования» для всех людей, независимо от их социального статуса, этнокультурных и языковых особенностей.

Если рассматривать социокультурную инклюзию в призме образования, то она фокусируется на:

- установлении доверительных отношений в школе между учащимися, родителями и учителями;

- уважительном отношении к культуре, языку и верованиям;

- предоставлении возможностей для учеников и их семей делиться информацией о своей культуре, традициях, обычаях;

- продвижении позитивных отношений с родителями других национальностей;

- обеспечении равного участия всех детей в школьной жизни.

Как уже было сказано ранее, социокультурная и образовательная инклюзия тесно связаны между собой. Что именно их объединяет и каковы их точки соприкосновения? 


\section{Социокультурная и образовательная инклюзия: точки соприкосновения}

Мы рассмотрели взаимосвязь образовательной и социальной инклюзии на трех уровнях: глобальном, локальном и внутриличностном.

\section{Глобальный уровень}

1. Инклюзивное образование снижает бедность, несправедливость в обществе, предоставляя доступ к культурным и образовательным услугам для всего общества.

2. Инклюзивное образование ведет за собой создание общества равных прав и возможностей, мирного сообщества.

3. Получая доступ к образованию, люди имеют шансы на трудоустройство, активное участие в общественной, политической и культурной жизни.

4. Принимая определенные усилия по развитию инклюзивного образования на национальном уровне, государства включаются в общий процесс разработки международной политики в данной области (через создание международных фондов, организаций, партнерских объединений).

В то же время, социокультурная инклюзия также оказывает влияние на развитие инклюзивного образования. В обществе, где признаются равные права и возможности, ценится культурное разнообразие, наиболее развито инклюзивное образование:

- продвигается участие детей и родителей в образовательной и культурной деятельности;

- снижается дискриминация в образовании, устраняются барьеры в обучении;

- политика в области образования отвечает нуждам всех детей, независимо от их возможностей, социального статуса, культурных особенностей;

- признается право всех детей на получение качественного образования.

Обеспечение идеи «социокультурной инклюзии» на глобальном уровне - серьезная и системная задача. Международные фонды, государственно-частные партнерства, национальные правительства могут объединяться для проведения совместной политики в области инклюзивного образования, социальной инклюзии, оказания финансовой поддержки в форме грантов для реализации различных социальных и культурных проектов. Они, в свою очередь, способствуют дальнейшему активному участию людей с ограниченными возможностями здоровья (ОВ3) в общественной, культурной, спортивной жизни, предоставлению доступа к образовательным услугам. Также существует немало международных Инициатив таких организаций, как ЮНЕСКО, ЮНИСЕФ, направленных на оказание помощи другим государствам в подготовке педагогов для работы с особыми детьми (семинары, круглые столы, совместные конференции, исследования). Они оказывают организационную и техническую помощь государствам, осуществляют мониторинг и оценку эффективности национальной образовательной политики.

Локальный уровень (уровень страны, города, образовательной организации)

На локальном уровне, рассматривая взаимосвязь инклюзивного образования и социокультурной инклюзии, важно учитывать политику государства в социальной, культурной и образовательной сферах. Также большое значение имеют этнокультурные особенности государства, установки, принятые в обществе, особенности национального восприятия тех или иных социальных явлений.

1. Национальное самосознание того или иного этноса (национальная сплоченность или разрозненность) оказывает серьезное влияние на поддержку или непринятие инклюзивного образования. В то же время инклюзивное образование может привести к социокультурной инклюзии, национальному сплочению в государстве.

2. Этнокультурные особенности государства (культурные взгляды, традиции, обычаи, национальный менталитет) влияют на понимание «инклюзии» и, следовательно, на развитие инклюзивного образования. И, наоборот, инклюзивное образование порождает предпосылки для социокультурной инклюзии в том или ином государстве.

На уровне образовательной организации также прослеживается взаимосвязь между социокультурной инклюзией и особенностями развития в ней инклюзивного образования.

Нами предложено обозначить некую «область социокультурного включения» - ту область, где происходит процесс включения субъектов образования, их отношений, установок, программ, мероприятий школы в социокультурное пространство. На рисунке 1 показано, что именно здесь осуществляется повышение социокультурной компетенции педагогов, учащихся, родителей, формируется толерантность и уважительное отношение к другой культуре, активно вовлекаются в социальную и культурную жизнь школы все участники образовательного процесса, учителя совместно формируют стратегию образования. Представленная нами «область социокультурного включения» строится на принципе диалога культур, уважения и взаимной поддержки.

\section{Личностный уровень}

Инклюзивное образование способно не только изменить культуру школы, политику государства, нацио- 


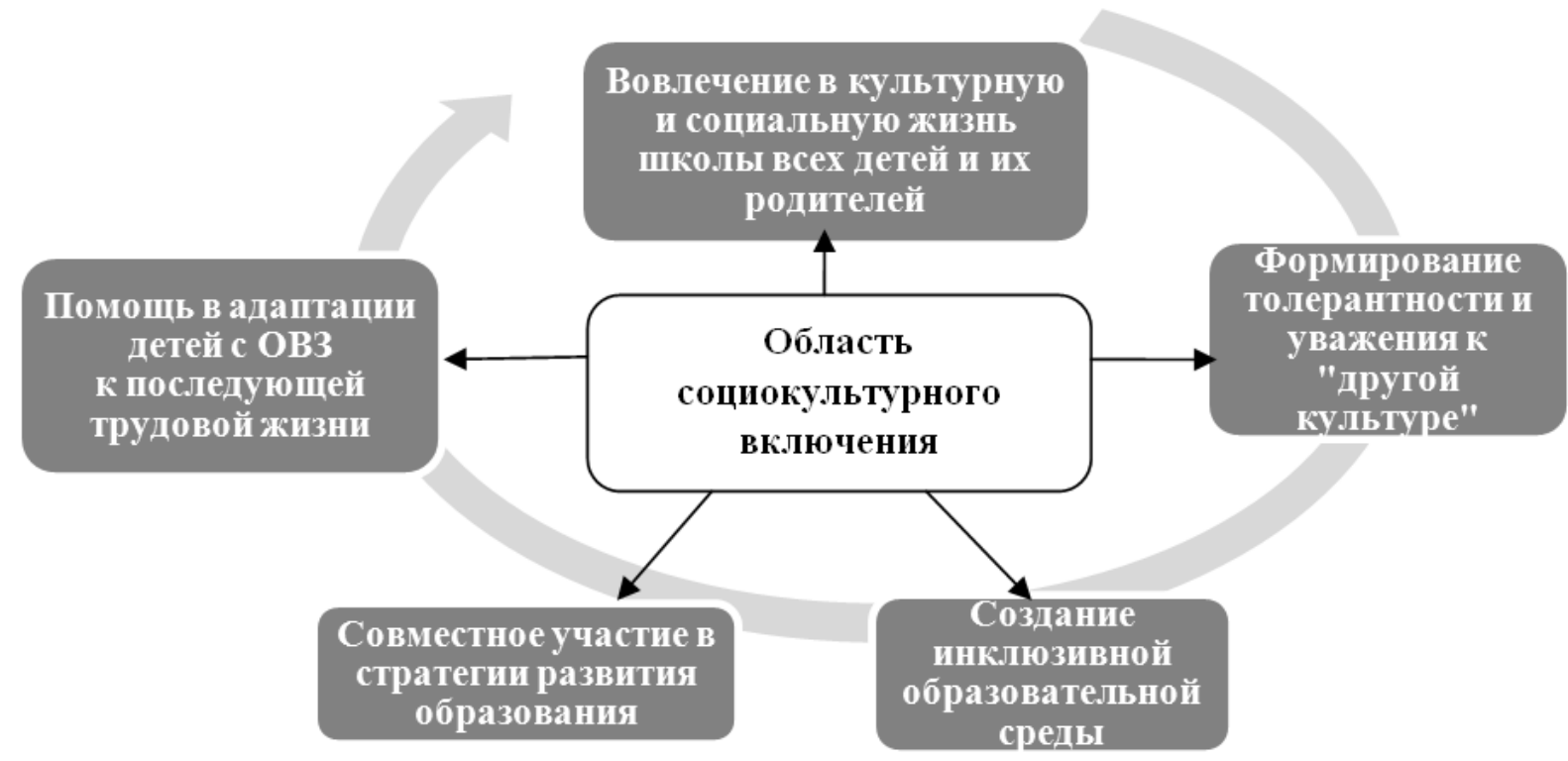

Рис. 1. Область социокультурного включения на уровне образовательной организации

нальное восприятие в целом. Прежде всего, оно меняет каждого человека, предоставляя ему возможность почувствовать себя принятым обществом, друзьями, педагогами, полноценным участником культурной и социальной жизни.

Н. Закариа [10] из Национального Университета Малайзии провел интересное исследование, которое показало, какое именно воздействие оказывает инклюзивное образование на Я-концепцию учащихся с особыми образовательными потребностями. В трудах Роджерса Я-Концепция включает в себя убеждения, чувства, восприятие, установки и ценности, которые имеет данный человек [11]. Кроме того, самооценка также характеризует то, как человек думает о себе и об отношении других к нему. Я-концепция делится на два типа: положительная и отрицательная. Безусловно, Я - концепция влияет на последующий процесс включения этих студентов в социальную и культурную жизнь в образовательной организации и за ее пределами.

В исследовании принимали участие 52 учащихся в возрасте от 8 до 15 лет из 10 школ штата Селангор (Малайзия). Использовалась шкала оценки Я-Концепции Пирс-Харриса, состоящая из шести сфер: счастье и удовлетворенность, адаптивное поведение, отсутствие тревоги и беспокойства, внешность, интеллектуальный и внутришкольный статус и популярность. По результатам опроса было выявлено, что 69, 23 \% учащихся с ОВ3 имели средний уровень Я-концепции, 23, 08 \% - достаточно высокий уровень и 7,69\% - низкий уровень. Этот результат показывает, что большинство учащихся имеют средний уровень самооценки. Также результаты свидетельствуют, что 80 \% учащихся чувствуют себя счастливыми.
Данное исследование говорит о том, что большинство учащихся с ОВЗ имеют положительное социальное восприятие и хорошие отношения со сверстниками, признание с их стороны. Также учащиеся счастливы, потому что у них есть возможность учиться со сверстниками в обычных условиях.

Таким образом, инклюзивное образование не только помогает учащимся с ОВ3 установить дружеские отношения с другими учениками и учиться в той же среде, иметь позитивное отношение со стороны сверстников, но и главное быть частью сообщества и развивать свой потенциал в академических и неакадемических аспектах. Эффективное инклюзивное образование приносит пользу таким учащимся, потому что они могут повысить свой потенциал во всех аспектах, быть включенными в социокультурное пространство благодаря формированию позитивной самооценки, что в дальнейшем делает учеников счастливыми и успешными людьми.

Иначе можно взглянуть на взаимосвязь инклюзивного образования и социокультурной инклюзии в призме поликультурного образования. В данном случае учебный процесс осуществляется с учетом культурных, лингвистических особенностей учащихся, их мировоззрения и мироощущения, религии, этнических стереотипов. «Область социокультурного включения», о которой мы говорили ранее, будет создана путем:

1. вовлечения учащихся разных национальностей, социального статуса в совместную культурную и творческую деятельность (выступления, творческие проекты);

2. наполнения процесса обучения социокультурным содержанием (включение в учебную программу 




Таб.1. Взаимосвязь образовательной и социокультурной инклюзии

культуроведческих, лингвострановедческих, языковых компонентов), имеющим духовно-нравственную и гуманную направленность.

Важно, чтобы и педагоги были включены в такое «социокультурное пространство» в процессе обучения. Это может быть достигнуто через повышение межкультурной компетенции педагогов (тренинги, семинары, практикумы, курсы повышения квалификации). Такие мероприятия не только помогут педагогам познать «другую» культуру учащихся, организовать эффективную межкультурную коммуникацию, но и проявить толерантность и уважение к культурным особенностям учеников. Это и есть один из важнейших принципов инклюзивного образования.

В таблице 1 представлена взаимосвязь социокультурной и образовательной инклюзии на трех уровнях, описанных нами выше.

\section{Выводы}

На глобальном уровне, говоря о внедрении идей инклюзивного образования, происходит становление гуманного общества, где ценятся способности и возможности каждого человека. Государства, организации, партнерства активно вовлечены в совместные социокультурные и образовательные проекты по развитию инклюзивного образования.

На локальном уровне (города, села, школы) меняется национальное восприятие инклюзивного образования, отношение к детям с особыми потребностями в развитии. Социокультурная инклюзия проявляется здесь на уровне образовательной организации, где родители, педагоги и дети активно участвуют в создании доступной, гуманной, «коллаборативной» образовательной среды, решения принимаются в сотрудничестве.

На межличностном и внутриличностном уровнях инклюзивное образование способствует повышению самооценки учащихся, адаптации их к учебной и внеучебной деятельности, и, наконец, активному включению участников образовательного процесса в межкультурную коммуникацию, их культурному и языковому взаимообогащению.

Таким образом, на стыке социокультурной и образовательной инклюзии возникает определенная «область социокультурного включения», где каждый чувствует себя принятым, ценным для школы, города, страны и общества в целом.

\section{ЛИТЕРАТУРА}

1. Stubbs S. Inclusive Education. Where are the few resources. 2008. 156 p. URL: https://www.eenet.org.uk/resources/docs/IE\%20few\%20resources\%202008.pdf

2. Ахметова Д.З., Нигматов 3.Г., Челнокова Т.А., Юсупова Г.В. Педагогика и психология инклюзивного образования: учебное пособие. - Казань; Познание, 2019,174 c

3. Пургина Е.И. Философские основы инклюзивного образования в контексте Специального Федерального государственного образовательного стандарта 
для детей с ограниченными возможностями здоровья // Педагогическое образование в России. 2014. № 2. С. 152-156.

4. Назарова Н.М. Теоретические и методологические основы образовательной интеграции // Инклюзивное образование: методология, практика, технология: материалы международной научно-практической конференции. 2011. С.9-11

5. Pandit P. Philosophy of inclusion - problems and challenges // International Journal of Academic Research and Development. 2017. Vol. 2 (5). P.665-673

6. Spratt J., Florian L. Applying the principles of inclusive pedagogy in initial teacher education: from university based course to classroom action // Revista de Investigación en Educación. 2013. № 11 (3). P. 133-140

7. Выготский Л.С. Собр. соч.: в 6 т. / под ред. А.М. Матюшкина. М., 1983. Т. 3, 368 с.

8. Robo M. Social inclusion and Inclusive Education // Academicus International Scientific Journal. 2014. Issue 10. P. 181-191

9. UNESCO - Cultural Inclusion. URL: http://www.unesco.org/new/en/social-and-human-sciences/themes/urban-development/migrants-inclusion-in-cities/goodpractices/cultural-inclusion/

10. Zakaria N., Tahar M. The Effects of Inclusive Education on the Self-Concept Of Students with Special Educational Needs // Journal of ICSAR. 2017. Vol. 1. № 1. P. 2531. URL: https://doi.org/10.17977/um005v1i12017p025

11. Rogers C. Client-Centered Therapy.1951. Boston:Houghton Mifflin. 560 p.

\footnotetext{
(c) Сучков Максим Александрович (maksim-suchkov@inbox.ru).

Журнал «Современная наука: актуальные проблемы теории и практики»
}

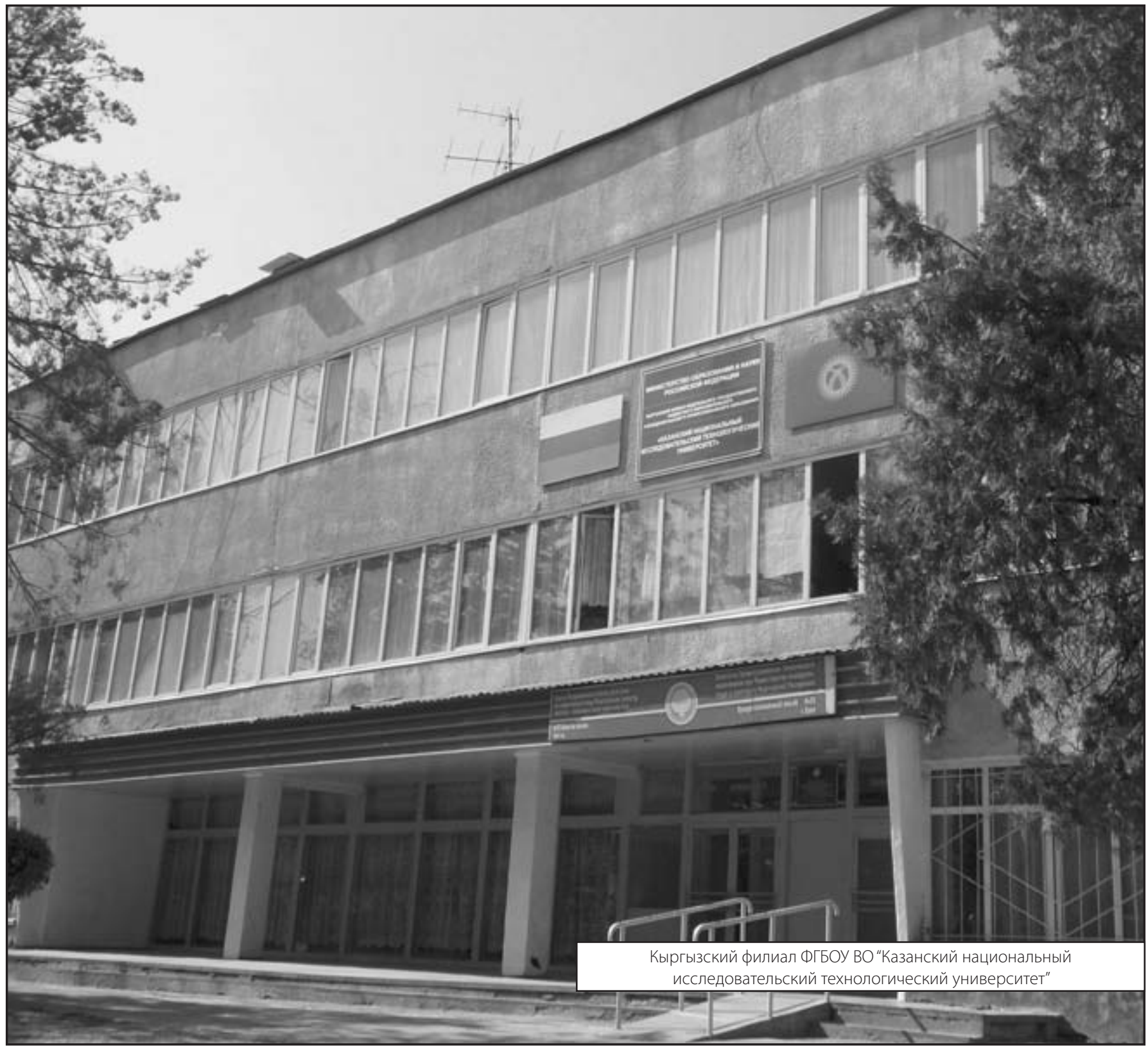

